\title{
Examining Student Identification With The Alumni Organization At A 4-Year Commuter Campus
}

John J. Newbold, Sam Houston State University, USA

Sanjay S. Mehta, Sam Houston State University, USA

Patricia R. Forbus, Sam Houston State University, USA

\begin{abstract}
Past research has identified several institutional and individual antecedents that lead to greater intent to support an organization. This paper takes an organizational identification approach in developing an Alumni Relationship Model (ARM) that can be used by universities to generate greater support for their Alumni services activities. This paper shows that by going beyond traditional organizational identification models and by introducing new variables, it is possible to broaden and enrich both practice and theory of organizational identification within a university setting.
\end{abstract}

Keywords: psychographics, institution identification, institution commitment, involvement, alumni association, organizational identification, alumni support

\section{INTRODUCTION}

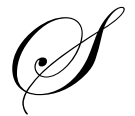

ince the 1980's, many public universities in the United States have evolved from "state" universities to "state-supported" universities. As universities struggle to generate additional revenues to overcome the shortfall created by state legislators, they are developing more creative ways to raise money. This coupled with increases in university budgets (which continue to outpace inflation), has put tremendous pressure on university administration to raise additional funds (Caboni, 2003).

Probably one of the best and most successful methods of generating additional revenues is through alumni support. Most universities today are investing millions of dollars on their alumni associations. While some of this money is being spent in improving infrastructures (e.g., building better and larger alumni centers), most of it is being spent on building better relationships with past graduates (Okunade and Berl, 1997). Since these former students hold diplomas that bear the name of the university, it is believed that they will have an affinity towards the institution. Alumni gifts typically fund student financial aid (e.g., scholarships), subsidize faculty development allocations (e.g., travel and grants), and support other needs of the academic programs (Okunade and Berl, 1997).

Even though Customer Relationship Management (CRM) is not a new concept, its importance today cannot be understated. It is an organized business method to build long lasting and mutually beneficial relationships (Chen, 2008). To assist alumni directors practice better CRM, this paper will undertake this issue as a marketing management problem rather than as an organizational management problem. More specifically, the widely used and practiced principles of marketing will be used to develop a testable CRM model. Additionally, several hypotheses regarding institution and individual antecedents will be stated and empirically tested.

\section{LITERATURE REVIEW}

As a special form of social identification, organizational identification refers to seeing oneself as a part of an organization and conceptualizing oneself in terms of membership in this organization (Korotov, 2003). To the 
extent that individuals identify with a group, they experience the successes and failures of the group as their own and incorporate the dominant attitudes and values of the group as their own (Korotov, 2003). Organizational identification occurs when a member adopts the defining characteristics of the organization as defining characteristics for themselves (Bamber and Venkataraman, 2002). Organizational identification occurs when a member chooses an alternative that best promotes the perceived interests of the organization. Organizational identification is an evolutionary process, where an organization's culture may influence the level of identification with the organization (Schrodt, 2002). Organizational identification is different from commitment, which does not appear to be organization specific since an individual may transfer attachment to a competing organization because of similar goals and values. Researchers have applied organizational identification in a variety of settings. Not only to employees of work organizations, but also to different types of psychological group members such as college alumni (Bamber and Vankataraman, 2002).

Organizational identification leads to favorable behavior and greater intention to support an institution of higher education. Caboni (2003) determined that there is a positive relationship between involvement, perception of educational effectiveness, perception of organizational prestige, and subsequent organizational identification. In reviewing the relationship between these constructs, a better understanding can be developed into how the involvement of undergraduates influences their connection to their alma maters. Okunade and Berl (1997) determined that university alumni, who tend to identify with their alma mater, tend to be strongly affected by organizational identification factors of prestige and sentimentality. Marketing principles play a strong role in developing this organizational identification. Marketing, purposely directed toward students may bring about an improved student interest towards the marketed university (Rudd \& Mills, 2008).

Mael and Ashforth (1992) developed their own relationship model. They developed the idea of the bonding with an organization and related organizational identification to a number of factors including the perception of organizational prestige, participation in activities, and pride and satisfaction with organizational programming. An in depth review to the relationship model presented by Mael and Ashforth (1992) along with other research resulted in an "Alumni Relationship Model (ARM)" with the development of several hypotheses (see Figure 1).

Figure 1

\section{Alumni Relationship Model}

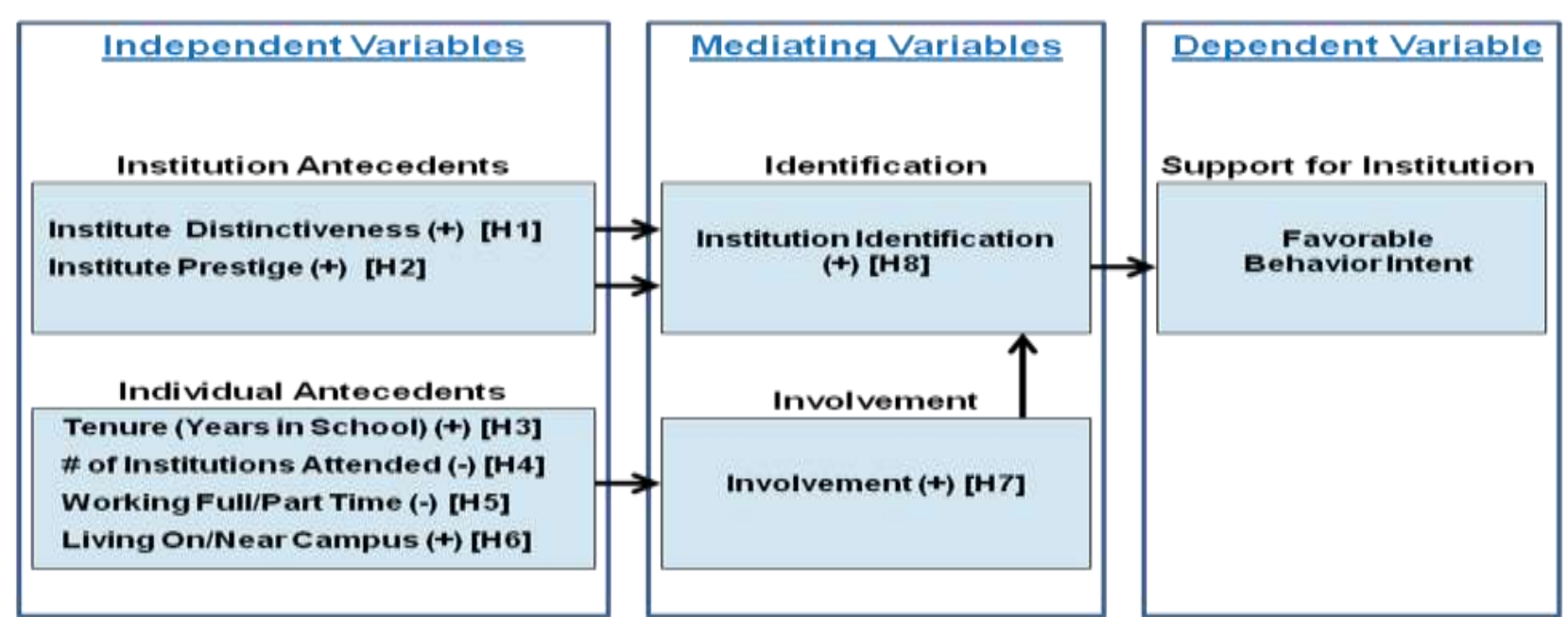

Antecedents are factors representing the independent variables which influence the dependent variables through mediating variables. To assist in designing the instrument that was used for a follow-up descriptive research study, 
some of the key constructs and their conceptual definitions that were identified in the literature are discussed below (Mael and Ashforth, 1992).

\section{Antecedents}

1. Institutional Antecedents denote the precursor attributes of the university.

a. "Institute Distinctiveness" includes things that differentiate the university from other institutions (e.g., unique programs, small classes, attractive campus).

b. "Institute Prestige" is comprised of things that students would like to identify with the university so as to boost their individual self-esteem (e.g., reputation, would recommend to others).

2. Individual Antecedents represent the characteristics of the students. These independent variables can be measured using single item measures.

a. "Tenure" - years at the institution

b. "Number of Institutions Attended" - number of institutions of higher education attended

c. "Working Full/Part Time" - working full or part time during the school year

d. "Living On/Near Campus" - living on or near campus

\section{Mediating Variables}

1. Just as antecedents are critical in measuring consequences, so are the mediating variables.

a. "Identification" - a mediating variable that can assist alumni directors determine how strongly students identify with the university (e.g., proud, embarrassed, criticize).

b. "Involvement" - how integrated the students are in various activities associated with the university (e.g., mentoring and interaction with faculty, extracurricular). While involvement generally refers to time and effort invested, here it refers to participation in organized activities offered by the institution.

\section{Dependent Variable}

1. "Institutional Intent" -- the independent variable of interest is one's intent to support the alumni association of the institution.

\section{HYPOTHESES}

\section{Hypotheses Related to Institutional Antecedents}

Organizational identification is related to perceived prestige of the university, the alumni's continued relationship with a mentor, and the alumni's inclination to benefit their former organization (Bamber and Venkataraman, 2002). A member of an organization compares his/her perceptions of an organization's identity with expectations for an ideal identity which results in significant affects on a member's level of involvement with the organization (Foreman and Whetten, 2002). Individuals who identified strongly with their university and viewed it as being prestigious, distinctive, and competitive with other higher education institutions were more likely to display favorable intentions to support the institution (Mael and Ashforth, 1992).

Hypothesis 1: Students who view the institution to be distinct are more likely to identify with the university. Hypothesis 2: Students who view the institution to be prestigious are more likely to identify with the university.

\section{Hypotheses Related to Individual Antecedents}

Scholars in social identity use the premise that people classify themselves and others based on various social or demographic groups (Foreman and Whetten, 2002). Social classification provides individuals with a means of defining themselves through a sense of belonging or identification with a particular group. By way of extension, organizational identification can be seen as essentially a subtype of social identification (Foreman and Whetten, 2002). Strong attachment leads to favorable organizational outcomes (Bamber and Venkataraman, 2002). Members 
have a tendency to identify more strongly with their individual social groups than with the organization as a whole, and that strength of identification is increased with years of tenure with the association (Schrodt, 2002). Transferring students generally tend to feel isolated and disconnected from the student body at a new school. Many will focus on getting their degree and graduating rather than interaction with their peers and forming lasting relationships (Pemberton, 2009). Universities with higher participation in fraternities and sororities have higher levels of giving associated with their alumni (Harrison, Mitchell, and Perterson, 1995). Students who work full time and live away from the campus are projected to participate less in school activities, campus social events, and be less involved with fellow students and faculty (Mehta, Newbold, and Forbus, 2008).

Hypothesis 3: Students who have been at the institution longer are more likely to be involved in activities sponsored by the university.

Hypothesis 4: Students who have attended other institutions (e.g., transferred) are less likely to be involved in activities sponsored by the university.

Hypothesis 5: Students who work during the school year are less likely to be involved in the activities sponsored by the university.

Hypothesis 6: Students who live on or near campus during the school year (i.e., not commuters) are more likely to be involved in activities sponsored by the university.

\section{Involvement}

Specific behaviors associated with involvement in an organization are potential outcomes of organizational identification. Participation in social activities increases social integration and interpersonal bonds with the institution (Caboni, 2003). Affective identification focuses on a member's positive feelings about their involvement in the organization, as well as their expressed sentiments of loyalty and desire to help the organization be successful (Foreman and Whetten, 2002). Alumni with relatives who have attended the college, and alumni who have played a varsity sport during college, are two groups very likely to financially support their former university (Wunnava and Lauze, 2001).

Hypothesis 7: Students who are involved and participate in various activities and/or organizations are more likely to be committed to the university.

\section{Identification}

Organizational identification consists of multiple dimensions. Attachment to an organization may manifest itself in many different forms, such as identification, loyalty, and internalization. Organizational identification is a promising contribution to determining loyalty and attachment to an organization (Bamber and Venkataraman, 2002).

Hypothesis 8: Students who identify with the university are more likely to have favorable behavior intent toward supporting the alumni association of the university.

\section{METHOD}

The cross-sectional survey research deployed to collect the data for this study was preceded by two types of exploratory research methodologies. First, a review of the literature was employed in numerous library database searches utilizing key words related to the subject matter. Second, four focus groups among the graduating seniors were conducted. Two groups consisted of students who were "most likely" to join the school's alumni association upon graduation. The other two groups consisted of students who were "least likely" to join. Some of the main issues that were discussed during the focus groups included memorable experiences at the university, involvement in clubs and associations, and the value proposition to joining the alumni association prior to or upon graduation.

\section{The Survey Instrument}

Since no secondary data existed to answer the specific relationships posited by the proposed ARM model, primary data was collected. Survey research methodology was employed. The survey instrument was a self- 
administered, structured, undisguised questionnaire. Besides the fact that this type of instrument is the fastest, least expensive, and most popular (Aldrek and Settle, 1995), our primary motivation for selecting this form of instrument was that it was the most appropriate methodology given our sample frame, sample size, and time frame. To ensure quality (Churchill and Brown, 2007), attention was given to the actual designing of the questionnaire in terms of proper phrasing of the questions, the layout of various sections, and consistent use of a ten-point scale.

Recognizing the fact that the instrument was meant to measure ideas and concepts that are abstract and non-observable, extra care was taken in designing the questionnaire. A pilot study was conducted with a sample of the population (i.e., graduating seniors) to determine accuracy of instructions, wording of the questions, and appropriateness of scale. Because students were being asked how likely they were to provide financial support to their alma mater, extra care was taken to eliminate any ambiguity in the questionnaire.

Approximately 3-4 items were developed to represent each construct under investigation. The survey took between 10 and 15 minutes to complete. To encourage participation from respondents, all completed responses were eligible to participate in a random drawing.

\section{Sample Selection}

The population under study was seniors, those expecting to graduate within one year, at a midsize, "statesupported" university in Texas. To guarantee representation from the population, stratified sampling was used. Both gender and ethnicity were used to create the stratas.

Chi-square goodness of fit test was also performed on the sample to determine the accuracy and representation of the sample to the population proportions. Scales were created and assessed with Chronbach Alphas. Relationships between interval-level variables were assessed utilizing the Pearson Correlation Co-efficient. Finally, nominal (classification) data were analyzed by comparing the means of independent groups via the t-test.

\section{FINDINGS}

The ARM Model as previously outlined is reprised below in Figure 2, annotated with the resulting correlation coefficients.

Figure 2

\section{Alumni Relationship Model}

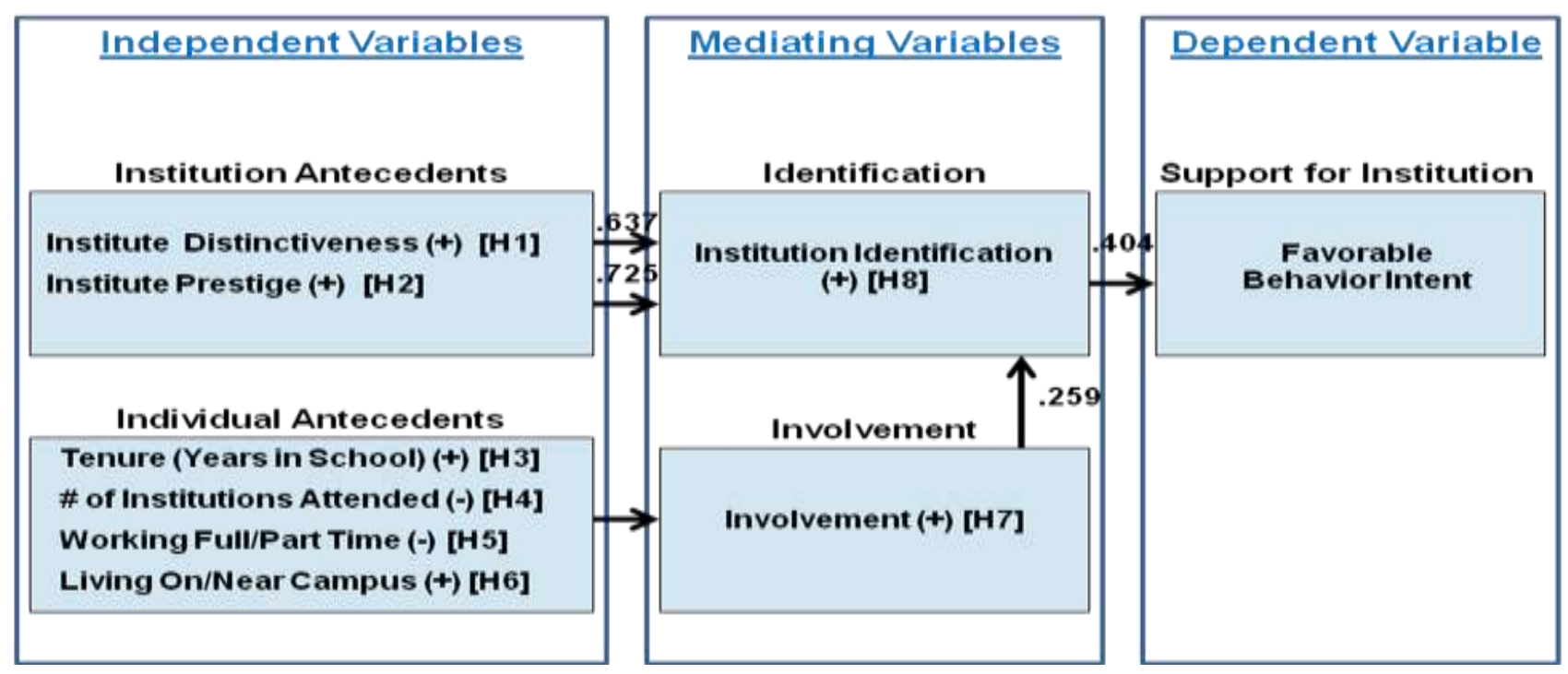


In general, support was found for many (but not all) of our hypothesized relationships. While all of the correlations were statistically significant, several key relationships appear to show relatively weak correlations. Similarly, some of the means difference were found not to be significantly different. Overall, the proposed Alumni Relationship Model (ARM) appears to merit further research and development.

Table 1

\begin{tabular}{|c|c|c|c|c|}
\hline \multicolumn{5}{|c|}{ Correlation between Institutional Antecedents and Identification } \\
\hline \multicolumn{2}{|c|}{ Hypothesis } & Item & Correlation & Supported \\
\hline \multicolumn{2}{|c|}{$\begin{array}{l}\mathrm{H}_{1}: \text { Students who view the institution to be distinct are more likely to identify } \\
\text { with the university. }\end{array}$} & Distinctness & 0.637 & $\begin{array}{l}\text { Strongly } \\
\text { Supported }\end{array}$ \\
\hline \multicolumn{2}{|c|}{$\begin{array}{l}\mathrm{H}_{2}: \text { Students who view the institution to be prestigious are more likely to } \\
\text { identify with the university }\end{array}$} & Reputation & 0.725 & $\begin{array}{l}\text { Strongly } \\
\text { Supported }\end{array}$ \\
\hline \multicolumn{5}{|c|}{ Comparison of Means - Individual Antecedents } \\
\hline Hypothesis & Item & Means & p-value & Supported \\
\hline $\begin{array}{l}\mathrm{H}_{3}: \text { Students who have been at the } \\
\text { institution longer are more likely to } \\
\text { be involved in activities sponsored by } \\
\text { the university. }\end{array}$ & $\begin{array}{l}\text { Attended } 2 \text { years or less } \\
\text { Attended more than } 2 \text { years }\end{array}$ & 4.45 & 0.398 & $\begin{array}{l}\text { Not } \\
\text { Supported }\end{array}$ \\
\hline $\begin{array}{l}\mathrm{H}_{4}: \text { Students who have attended other } \\
\text { institutions (e.g., transferred) are less } \\
\text { likely to be involved in activities } \\
\text { sponsored by the university. }\end{array}$ & $\begin{array}{l}\text { Only attended this University } \\
\text { Attended } 2 \text { or more schools }\end{array}$ & 4.76 & 0.003 & $\begin{array}{l}\text { Strongly } \\
\text { Supported }\end{array}$ \\
\hline $\begin{array}{l}\mathrm{H}_{5}: \text { Students who work during the school } \\
\text { year are less likely to be involved in } \\
\text { the activities sponsored by the } \\
\text { university. }\end{array}$ & $\begin{array}{l}\text { Not working } \\
\text { Working }\end{array}$ & 4.54 & 0.968 & $\begin{array}{l}\text { Not } \\
\text { Supported }\end{array}$ \\
\hline $\begin{array}{l}\mathrm{H}_{6}: \text { Students who live on or near campus } \\
\text { during the school year (i.e., not } \\
\text { commuters) are more likely to be } \\
\text { involved in activities sponsored by } \\
\text { the university. }\end{array}$ & $\begin{array}{l}\text { Non-Commuter } \\
\text { Commuter }\end{array}$ & $\begin{array}{l}4.84 \\
3.40\end{array}$ & 0.000 & $\begin{array}{l}\text { Strongly } \\
\text { Supported }\end{array}$ \\
\hline \multicolumn{5}{|c|}{ Correlation between Involvement and Identification } \\
\hline \multicolumn{2}{|l|}{ Hypothesis } & Item & Correlation & Supported \\
\hline \multicolumn{2}{|c|}{$\begin{array}{c}\mathrm{H}_{7} \text { : Students who are involved and participate in various activities and/or } \\
\text { organizations are more likely to be committed to the university. }\end{array}$} & Involvement & 0.259 & $\begin{array}{l}\text { Weakly } \\
\text { Supported }\end{array}$ \\
\hline \multicolumn{5}{|c|}{ Correlation between Identification and Interest in Joining Alumni Association } \\
\hline \multicolumn{2}{|c|}{$\begin{array}{l}\mathrm{H}_{8}: \text { Students who identify with the university are more likely to have } \\
\text { favorable behavior intent toward supporting the alumni association of } \\
\text { the university. }\end{array}$} & Identification & 0.404 & $\begin{array}{l}\text { Partially } \\
\text { Supported }\end{array}$ \\
\hline
\end{tabular}

Relative to the Institution Antecedents, both institution distinctiveness and institution prestige are found to be positively correlated to Institution Identification. The results for Individual Antecedents were more mixed, with certain proposed independent variables (i.e., tenure at the school, work status) found to be less useful than hypothesized in terms of their role in increasing student involvement. However, as hypothesized, it appears that transfer students have a lower level of involvement with the institution. Similarly, as hypothesized, commuter students exhibit lower levels of involvement with the institution. Individual antecedents are an area that bears more examination, as several individual-based factors are likely to be impacting levels of involvement. Future research is needed to better understand the balance of work and school lives for commuter and non-commuter students. It is difficult for universities to implement campus activities and programs when they don't fully understand the lives of either group. Commuter students, in theory, are sharing much of the same burden of work and school commitments and have less time for school functions. This would limit their involvement and, therefore, their identification with 
the university and support intent for the university. Perhaps research should be done at a large, traditional university with more students living either on campus or in the same town as the institution.

Involvement is shown to be positively correlated to identification, albeit at a lower level (0.259) than one might hope for if one were planning a marketing campaign. Further research is likely required in better understanding the nature of the activities that constitute "involvement", in order to better determine those that drive higher levels of a sense of identification. Finally, as hypothesized, identification was shown to be positively correlated to stated intent to join the Alumni Association. However, as was seen with involvement-identification, the strength of the correlation was only moderate (0.404). It is possible that positive identification alone is not sufficient to drive positive intent to join an alumni association. Future research should be directed at trying to better understand situational factors such as current income, expected income, proximity to graduation date, marketing approach (appeal, execution style), as well as the manner in which the question is asked.

Despite some of the weaker-than-desired correlations between key variables, the hypothesized Alumni Relationship Model (ARM) confirms nearly all of the hypothesized relationships. It confirms the importance of properly understanding your various student constituencies before developing marketing appeals to join a university alumni association, as varying levels of involvement and identification will impact receptivity to institution marketing efforts.

\section{CONCLUSION}

The research explored the associations among features of organizational culture and organizational identification. Results suggested that the dimensions of the institutional antecedents (i.e., institution being distinct and prestigious) and the individual antecedents (i.e., the number of institutions attended and living on or near the campus) maintained a positive, significant relationship with organizational identification. This means that if universities want their alumni to identify with the institution they must continue to make stride in improving the reputation of the university and making the university distinct and different then other universities in the area (i.e., stress its comparative advantage). Next, if universities want their alumni to identify with the university, they may need to segment the university population more carefully (i.e., adopt a niche based strategy). That is, Alumni Associations should "target" those students who live on or near campus and have attended only their university (rather than targeting all their graduates).

While previous research supported the hypotheses for tenure at the university (i.e., how long the student has been attending the university) and whether students are working or not working, our survey resulted in no support and therefore a weak relationship. One of the contributing factors believed to have impacted these results is that the survey was conducted in a campus environment with low student involvement in university-related activities (e.g., very few students attend sporting events). It is believed that the significance is skewed in part because a large number of the student population is classified as commuter students. This fact hinders there ability to become apart of the campus life through involvement with fellow students and their professors. These results extend organizational research that has linked organizational identification with various socially constructed components of the organization.

While our research found some support for the relationship between students participating in various activities (e.g., intramural sports) and identification with the institution, the correlation was weak. Since a large percentage of the student body attended multiple universities, they may identify with the other institution rather than the one where the sample was collected.

Finally, our study found partial support for the idea that students who identify with the university will likely join the alumni association. While distinctiveness and prestige of the institution may favor institution identification, the fact that students at this university have low involvement and do not participate in university activity tends to produce a lack of support for the university alumni. 


\section{AUTHOR INFORMATION}

Dr. John J. Newbold earned his Ph.D. at St. Louis University in 1993. Currently, he is Associate Professor of Marketing at Sam Houston State University.

Dr. Sanjay S. Mehta earned his Ph.D. at the University of North Texas in 1999. Currently, he is Professor of Marketing at Sam Houston State University

Patricia R. Forbus earned her MBA from the University of Arkansas in 1997 and has completed post-graduate work at Sam Houston State University working toward a MEd. She is retired from AT\&T/Lucent/SBC and has worked as a Business Development Volunteer for the Peace Corps in the Ukraine.

\section{REFERENCES}

1. Aldrek, Pamela L. and Robert Settle. The Survey Research Handbook. $2^{\text {rd }}$ edition. McGraw-Hill Irwin, 1995.

2. Bamber, Michael E. and Venkataraman, Iyer. Big 5 Auditor' Professional and Organiztional Identification. Auditing: A Journal of Practice and Theory, Vol. 19, No. 2, 2002.

3. Caboni, Timothy C. Organizational Identification and the Voluntary Support of Higher Education. Paper presented at the Association for the Study of Higher Education, Portand, Oregan, 2003.

4. Chen, Kuan C. The Dynamic Structure of Customer Relationship Management with Implications for Business Implementation. Journal of Business \& Economics Research, Vol. 6, No. 6, pp. 129-138, 2008.

5. Churchill, Gilbert A. Jr. and Brown, Tom J. Basic Marketing Research. $6^{\text {th }}$ edition. Thomson Southwestern, 2007.

6. Foreman, Peter and Whetten, David A. Members' Identification with Multiple-Identity Organizations. Organization Science, Vol. 13, No. 6, pp. 618-635, 2002.

7. Harrison, William B., Mitchell, Shannon K. and Peterson, Steven P. Alumni Donations and Colleges' Development Expenditures: Does Spending Matter? American Journal of Economics and Sociology, Vol. 54, No. 4, pp. 397-412, 1995.

8. Korotov, Konstantin. Identity and Identification: An Organizational Perspective. Paper presented at the INSEAD FIDS Workship, Brussels, 2003.

9. Mael, Fred and Ashforth, Blake. Alumni and Their Alma Mater: A Partial Test of the Reformulated Model of Organizational Identification. Journal of Organizational Behavior, Vol. 13, pp. 103-123, 1992.

10. Mehta, Sanjay S., Newvold, John J., and Forbus, Patricia R. Non-Traditional Students: Today's Higher Education Environment. A paper presented at the January, 2009, conference of The International Academy of Business and Public Administration Disciplines, Orlando, FL, 2009.

11. Okunade, Albert A. and Berl, Robert L. Determinants of Charitable Giving of Business School Alumni. Research in Higher Education, Vol. 38, No. 2, pp. 201-214, 1997.

12. Pemberton, Steve. Road to College. Journal of Marketing for Higher Education, 2009. Retrieved from http://colleges.collegetoolkit.com/guides/transfer/restransfer.aspx

13. Rudd, D. and Missl, R. Expanding Marketing Principles for the Sale of Higher Education. Contemporary Issues in Education Research, Vol. 1, No. 3, pp. 41-52, 2008.

14. Schrodt, Paul. The Relationship Between Organizational Identification and Organizational Culture: Employee Perceptions of Culture and Identification in a Retail Sales Organization. Central States Speech Association.Communication Studies, 2002. Retrieved from FindArticles.com http://findarticles.com/p/articles/mi_qa3669/is_200207/ai_n9092863

15. Wunnava, Phanindra and Lauze, Michael. Alumni Giving at a Small Liberal Arts College: Evidence from Consistent and Occasional Donors. Economics of Education Review, Vol. 20, No. 6, pp. 533-543, 2001. 